\title{
Study of Rock Mechanic Property and Mineralogy Relationship of the Huai Hin Lat Formation, Sap Phlu Basin, Northeastern Thailand: Implications for Understanding of Shale Gas Reservoir Rock
}

\author{
Boonnarong Arsairai ${ }^{*}$, Nawarak Ruenmai ${ }^{1}$, Qinglai Feng $^{2}$, Chongpan Chonglakmani ${ }^{1}$ \\ ${ }^{1}$ School of Geotechnology, Institute of Engineering, Suranaree University of Technology, Nakhon Ratchasima, Thailand \\ ${ }^{2}$ State Key Laboratory of Geological Processes and Mineral Resources, China University of Geosciences, Wuhan, China \\ Email: *rong_geo@hotmail.com
}

How to cite this paper: Arsairai, B., Ruenmai, N., Feng, Q.L. and Chonglakmani, C. (2019) Study of Rock Mechanic Property and Mineralogy Relationship of the Huai Hin Lat Formation, Sap Phlu Basin, Northeastern Thailand: Implications for Understanding of Shale Gas Reservoir Rock. Open Journal of Geology, 9, 718-721. https://doi.org/10.4236/ojg.2019.910084

Received: August 17, 2019

Accepted: September 22, 2019

Published: September 25, 2019

Copyright $\odot 2019$ by author(s) and Scientific Research Publishing Inc. This work is licensed under the Creative Commons Attribution International License (CC BY 4.0).

http://creativecommons.org/licenses/by/4.0/ (c) (i) Open Access

\begin{abstract}
Thailand is lacked of gas that more information of probable (P2) and possible (P3) reserve data including shale gas can be acceptable to prove (P1) reserve data for new gas field. This research had implicated for understanding of unconventional reservoir rock by rock mechanical, micro-CT, and geochemistry analysis of the Huai Hin Lat Formation. The rock mechanical analysis is composed of average young's modulus, Poisson's ratio, and compressive strength of $1933.79 \mathrm{MPa}, 0.1472$, and $52.56 \mathrm{MPa}$. The average porosity of $6.89 \%$ consists of $5.41 \%$ and $1.48 \%$ of closed and open porosities. The average mineralogical results consist mainly of $57.60 \%$ and $42.40 \%$ of brittle and ductile minerals indicating more elasticity except Bed 6 . The Bed 6 is significantly higher quartz $(15 \%)$ and brittle minerals $(64 \%)$ indicating to easier fracture are, therefore, lower compressive strength $(25.93 \mathrm{MPa})$, young's modulus (1729.10 MPa) and Poisson's ratio (0.0705). The Beds 3B is slightly higher clay containing slightly higher closed porosity (5.46\%) but the Bed 14 is slightly higher brittle mineral indicating to slightly higher open porosity.
\end{abstract}

\section{Keywords}

Compressive Strength, Young's Modulus, Poisson's Ratio, Brittle Mineral, Porosity

\section{Introduction}

Since 2014, there were 3 gas fields in the Khorat Plateau that only two former gas 
fields are commercial [1]. Another gas field is the Dong Mun that was newly discovered. It is absolutely proved that a proved (P1) reserve data will belong to a probable (P2) and possible ( $\mathrm{P} 3)$ reserve data by more studying. Some researchers are interested in unconventional gas field especially shale gas. The Huai Hin Lat Formation is one among others that are tried to develop a new shale gas field. Source rock potential is successful by former researchers. Therefore, more understanding rock mechanic properties are key control evaluation of unconventional reservoir rock.

\section{Materials and Methods}

The Beds 2, 3B, 6, 9, and 14 are suitable to be measured and described based on rocks cropping out in the Ban Nong Sai section, which are composed mainly of shale, mudstone, marl, and limestone [2]. All samples were tested for assessing unconventional reservoir potential with methods as follow. A uniaxial compressive machine was used for measuring compressive strength, Poisson's ratio, young's modulus, and failure mode. A micro computed tomography (Micro-CT) method can be used to analyze the porosity by using Skyscan 1172 from scanned datasets. A Geochemical method can identify minerals by using an X'Pert PRO Dy 2198 basing on X-ray diffraction analysis.

\section{Results and Discussion}

The compressive strength, Poisson's ratio, and young modulus are shown in Table 1 with compressive longitudinal splitting [3]. The young's modulus of the Beds 6 and 9 is the lowest and highest, respectively. The high young's modulus is that a rock extremely expands conforming to positive relationship $\left(R^{2}=0.3849\right)$ as well as compressive strength and young's modulus relationship $\left(\mathrm{R}^{2}=0.3398\right)$. The compressive strength of the Beds 6,2 and 9 is increasing which suggests a relatively higher ductile property. Moreover, relationship between compressive strength and Poisson's ratio shows positive covariation $\left(\mathrm{R}^{2}=0.9978\right)$, which is very interrelated. It indicates that higher compressive strength relates to higher lateral expansion of sample under loading.

Results of mineralogical analysis are shown in Table 1 with higher content of clay. Matrixes contain clays of ductile minerals may lead to higher elasticity. Contrastingly, cracks are generated as easier under formation of higher brittle minerals. Clay of the Bed 6 is lower than the Beds 2 and 9 though quartz and feldspar are higher. Therefore, the Bed 6 is easily fractured with lower compressive strength of 25.93 MPa. The Poisson's ratio and young's modulus of the Bed 6 are conformable to compressive strength due to effects of lower elasticity. The ductile mineral of the Bed 2 is remarkably higher than the Bed 6. Conformably, higher elasticity affects the Bed 2 that compressive strength is higher as well as the Bed 9 is the highest.

According to all beds, only the Beds $3 \mathrm{~B}$ and 14 were scanned for porosity as shown in Table 1. The value of clay in Bed 3B is higher than that of the Bed 14. 
Table 1. Mineralogic fraction XRD, rock mechanic properties, and porosity data of the Ban Nong Sai section.

\begin{tabular}{ccccccccccccc}
\hline \multirow{2}{*}{ Beds } & \multicolumn{4}{c}{ Total minerals (\%) } & \multicolumn{4}{c}{ Rock mechanic properties } & \multicolumn{2}{c}{ Porosity (\%) } \\
\cline { 2 - 11 } & Zeolite & Quartz & Feldspar & Calcite & Dolomite & Clay & $\sigma_{c}(\mathrm{MPa})$ & $v$ & E (MPa) & Closed & Open & Total \\
\hline 14 & 3.00 & 7.00 & 20.00 & 21.00 & 5.00 & 44.00 & - & - & - & 5.35 & 1.68 & 7.03 \\
9 & 2.00 & 9.00 & 8.00 & 31.00 & 6.00 & 44.00 & 66.28 & 0.1898 & 2292.73 & - & - & - \\
6 & 3.00 & 15.00 & 10.00 & 32.00 & 4.00 & 36.00 & 25.93 & 0.0705 & 1729.10 & - & - & - \\
$3 B$ & 2.00 & 8.00 & 15.00 & 21.00 & 7.00 & 47.00 & - & - & - & 5.46 & 1.28 & 6.74 \\
2 & 2.00 & 6.00 & 18.00 & 25.00 & 8.00 & 41.00 & 65.46 & 0.1812 & 1779.54 & - & - & - \\
Average & 2.40 & 9.00 & 14.20 & 26.00 & 6.00 & 42.40 & 52.56 & 0.1472 & 1933.79 & 5.41 & 1.48 & 6.89 \\
\hline
\end{tabular}

Remark: $\sigma_{\mathrm{c}}$ is compressive strength, $v$ is Poisson's ratio, and $\mathrm{E}$ is young's modulus.

The higher quantitation of clay is conformed to gradually increase of their porosity. Loucks et al. [4] suggest that micropores can be generated through fine-grained rocks which are commonly slot-like or interspersed between curved clay plates by shrinkage from higher thermal alteration. Both beds containing closed porosity are slightly similar in quantitation due to effect as is known as clay. Moreover, open porosity of the Bed 14 is higher than another that is associated with higher brittle mineral. It can be fractured as naturally depending on brittle characteristics that affecting to slightly higher open porosity. The porosity of Beds 2 and 9 is similar to that of the Bed 14. Contrastingly, the Bed 6 may be significantly different from others.

\section{Conclusions}

Average mineralogical results consist mainly of $57.60 \%$ brittle mineral and $42.40 \%$ ductile mineral (clay) indicating more elasticity except Bed 6. The Bed 6 is of significantly higher percentage of brittle mineral (64\%) referring to easier fracture.

The Bed 6 is easily fractured with lower compressive strength of $25.93 \mathrm{MPa}$ as well as young's modulus (1729.10 MPa) and Poisson's ratio (0.0705) due to effects of lower elasticity. The young's modulus and Poisson's ratio of 2292.73 $\mathrm{MPa}$ and 0.1898 of the Bed 9, significantly higher than those of the Beds 2 (1779.54 MPa and 0.1812), are remarkably higher than those of the Bed 6. Conformably, higher elasticity affects the Beds 2 and 9 that are of higher values of compressive strength (1779.54 MPa and 2292.73 MPa). The Beds 3B and 14 were scanned for porosity of $6.74 \%$ and $7.03 \%$, respectively.

\section{Acknowledgements}

This study is supported by the Royal Golden Jubilee Program, the Thailand Research Fund (RGJ-TRF), NSFC (41172202), the China Geological Survey Program (1212011121256). Many thanks are conveyed to officials at China University of Geosciences (Wuhan) and Geomechanics Research Unit, the Center for Scientific and Technology Equipment, Suranaree University of Technology. This 
is a contribution to UNESCO/IUGS/IGCP 679.

\section{Conflicts of Interest}

The authors declare no conflicts of interest regarding the publication of this paper.

\section{References}

[1] D.M.F. (2014) Tan Tawan Gas Field.

http://www.dmf.go.th/index.php?act=epsummary\&sec=concession

[2] Arsairai, B., Wannakomal, A., Feng, Q. and Chonglakmani, C. (2016) Paleoproductivity and Paleoredox Condition of the Huai Hin Lat Formation in Northeastern Thailand. Journal of Earth Science, 27, 350-364.

https://doi.org/10.1007/s12583-016-0666-8

[3] Hudson, J.A. and Harrison, J.P. (1997) Engineering Rock Mechanics: An Introduction to the Principles. Elsevier Science, Amsterdam, Netherlands.

[4] Loucks, R.G., Reed, R.M., Ruppel, S.C. and Hammes, U. (2012) Spectrum of Pore Types and Networks in Mudrocks and a Descriptive Classification for $\mathrm{Ma}$ trix-Related Mudrock Pores. AAPG Bulletin, 96, 1071-1098.

https://doi.org/10.1306/08171111061 